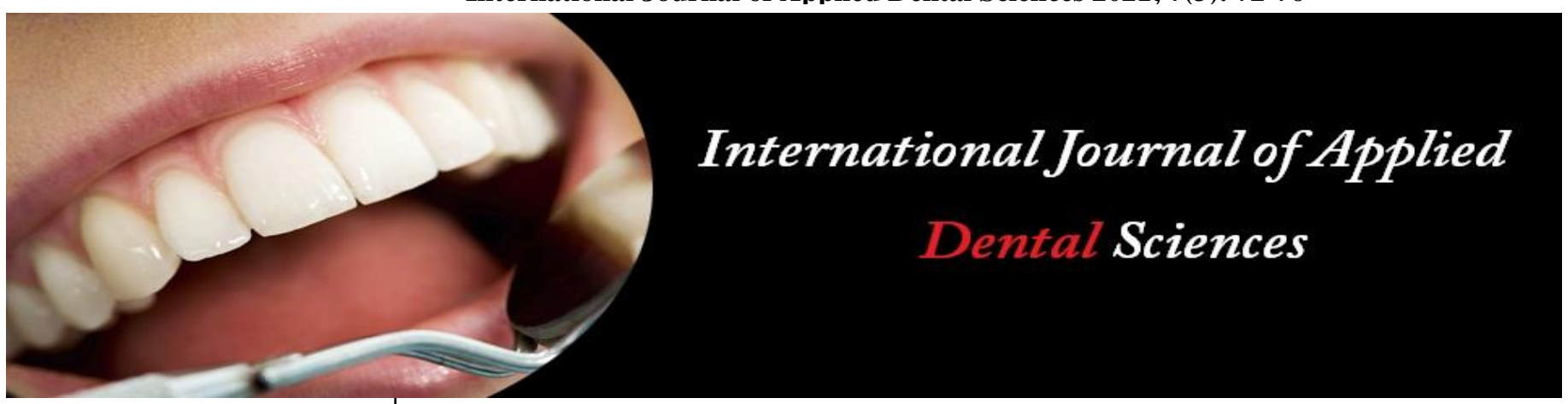

ISSN Print: 2394-7489

ISSN Online: 2394-7497

IJADS 2021; 7(3): 72-76

(C) 2021 IJADS

www.oraljournal.com

Received: 01-05-2021

Accepted: 03-06-2021

Bertha Garza Bernal

Master in Sciences Student,

Universidad Autonoma de Nuevo

Leon, Facultad de Odontologia,

Monterrey, Nuevo Leon, CP,

Mexico

Jose Elizondo Elizondo

Professor, Universidad Autonoma

de Nuevo Leon, Facultad de

Odontologia, Monterrey, Nuevo

Leon, CP, Mexico

Norma Cruz Fierro

Professor, Universidad Autonoma

de Nuevo Leon, Facultad de

Odontologia, Monterrey, Nuevo

Leon, CP, Mexico

Guadalupe Rosalia Capetillo-

Hernandez

Professor, Universidad

Veracruzana, Facultad de

Odontología, Veracruz, Mexico

Evelyn Guadalupe Torres Capetillo

Professor, Universidad

Veracruzana, Facultad de

Odontología, Veracruz, Veracruz,

Mexico

Maria Argelia Akemi Nakagoshi

Cepeda

Professor, Universidad Autonoma

de Nuevo Leon, Facultad de

Odontologia, Monterrey, Nuevo

Leon, CP, Mexico

Juan Manuel Solis-Soto

Professor, Universidad Autonoma

de Nuevo Leon, Facultad de

Odontologia, Monterrey, Nuevo

Leon, CP, Mexico

\section{Paediatric dentistry: Glass ionomer or giomer?}

\author{
Bertha Garza Bernal, Jose Elizondo Elizondo, Norma Cruz Fierro, \\ Guadalupe Rosalia Capetillo-Hernandez, Evelyn Guadalupe Torres \\ Capetillo, Maria Argelia Akemi Nakagoshi Cepeda and Juan Manuel \\ Solis-Soto
}

DOI: $\underline{\text { https://doi.org/10.22271/oral.2021.v7.i3b.1281 }}$

\section{Abstract}

Introduction: Giomers are composed of PRG fillers which in turn contain some ions, in addition to fluoride, which are beneficial to enamel so, it could be used for remineralization. Glass ionomer also contains fluoride and has been a commonly used material for many years.

Objective: to analyze information about its chemical composition, physical properties, chemical properties and application of S-PRG technology in comparison with glass ionomer.

Methodology: articles were searched in PubMed, Science Direct, Springer and EBSCO. Terms such as S-PRG OR GIOMER, S-PRG AND prevention, glass ionomer AND pediatric dentistry were used.

Results: S-PRG has a pre-reactive glass ionomer layer containing reactive ions that acts in contact with water and saliva, thus releasing ions that promote remineralization, bacterial control, etc. It has lower setting shrinkage compared to some ionomers and allows remineralization around the restoration and can be used as a restorative material for primary and permanent teeth. Glass ionomer has an acid-base reaction. By bonding glass ionomer filler to resins, it improves their properties, is successful in the presence of secondary caries and is well accepted as a restorative material after selective removal of carious tissue.

Conclusion: Both materials have fluoride releasing and recharging capabilities as well as restorative properties. However, giomer has better esthetic advantages. Further studies are required because giomers are relatively new.

Keywords: giomer, glass ionomer, pediatric dentistry, S-PRG filling

\section{Introduction}

There are materials that prevent demineralization and also have continuous fluoride release, among other properties that benefit enamel ${ }^{[1,2]}$.

Caries is one of the most prevalent oral diseases ${ }^{[3]}$.

Mineral depletion in the enamel causes hypomineralization, which increases susceptibility to caries ${ }^{[4]}$.

The prevalence of early childhood caries (ECC) is between $23 \%$ to $90 \%$ in several countries ${ }^{[5]}$. It has been observed that ECC is often not treated in time and therefore continues to have a high prevalence ${ }^{[6]}$. An association of molar incisor hypomineralization (MIH) with cavitated carious lesions was found ${ }^{[7]}$.

A toothpaste filled with surface pre-reacted glass ionomer (S-PRG) is more effective in demineralization than sodium fluoride at $1100 \mathrm{ppm}{ }^{[8]}$. In vitro studies have found glass ionomer (GI) materials to inhibit caries ${ }^{[9]}$.

There is no adequate review of giomers in comparison with glass ionomer, therefore, the aim of this study is to analyze the information about their chemical composition, physical properties, chemical properties and application of giomer in comparison with glass ionomer.

\section{Methodology}

Information from articles published in PubMed, Science Direct, Springer and EBSCO was analyzed with emphasis on the last 5 years. The quality of the articles was analyzed based on the PRISMA guidelines, i.e., identification, review, choice, and inclusion.
Corresponding Author:

Professor, Universidad Autonoma de Nuevo Leon, Facultad de Odontologia, Monterrey, Nuevo Leon, CP, Mexico 
The quality of the review was assessed using the measurement instrument for evaluating systemic reviews (AMSTAR-2) ${ }^{[10]}$.

Keywords used were: S-PRG OR giomer, S-PRG AND prevention, S-PRG AND primary teeth, surface pre-reacted glass-ionomer, composites AND color change, glass ionomer AND pediatric dentistry, giomer, (glass ionomer) AND (biomaterial).

\section{Results \\ 3.1 Chemical Composition}

\subsubsection{Giomer}

Materials containing pre-reactive glass ionomer filler (PRG) belong to the family of giomers, this term is a combination of glass ionomer plus polymer ${ }^{[11]}$ which, unlike compomers, use pre-activated silanized and dehydrated reactive fillers. These materials do not incorporate dehydrated acidic groups or nonfunctional acidic groups and therefore require the use of an adhesive prior to placement ${ }^{[12]}$. The formation of PRG is carried out by the acid-base reaction between flouroaluminosilicate glass (FASG) and polyalkenoic acid in the presence of water, and results in a siliceous hydrogel ${ }^{[13]}$. There are 2 types of filler with PRG technology: full glass ionomer filler (F-PRG) and surface glass ionomer filler (SPRG) ${ }^{[14]}$. The S-PRG filler is composed of 3 layers which in turn are composed as follows: the inner part of the filler containing the multifunctional fluorine-boron-aluminumsilicate glass, a middle layer of pre-reactive glass ionomer and a reinforced outermost layer ${ }^{[1,13,14]}$. The glass ionomer layer is composed of fluoride, aluminum, silicate, among others, which provide benefits to the dental organ according to their chemical properties ${ }^{[12]}$. In addition, it has a resin matrix which influences the biocompatibility and physicochemical properties of these materials ${ }^{[15]}$. It has an acid-base reaction when combining FASG glass powder and polyacrylic acid, which allows the glass ionomer phase to be stable ${ }^{[13]}$.

\subsection{Glass Ionomer}

The conventional glass ionomer presentation consists of an aqueous solution of polymeric acid and a glass powder. This material is prepared by making a homogeneous viscous mixture for subsequent application ${ }^{[16]}$. Those used for restorations generally consist of a mixture of polyacrylic acid (PAA) and tartaric acid that reacts with fluoroaluminosilicate glass in such a way that metal ions are released, which allows for bonding between the polyalkanoate chains ${ }^{[17]}$. In a recent study it was found that mixtures of linear and branched PAAs are suitable for improving the mechanical properties of new GIs ${ }^{[18]}$. The powder used for conventional ionomer usually contains aluminum oxide, silica and calcium fluoride ${ }^{[19]}$. These are materials that do not require phosphoric acid for adhesion to the tooth, since it's done by chemical bonding. Resin-modified glass ionomer (RMGIC), in addition, have resin free radical polymerization ${ }^{[17]}$.

Ionomers and giomers are distinct materials that are similar in composition. What stands out most about these two materials is their fluoride compound, since it's an extremely important ion for restorative treatments in pediatric dentistry.

\subsection{Physical Properties \\ 3.3.1 Giomer}

The water absorption mechanism that giomers have, is greater than that of some resin materials, this property is what allows the release of fluoride and other compounds from the S-PRG filler but large amount of water, has a negative result. In addition, it has been found to have greater discoloration compared to other resins ${ }^{[20]}$. On the other hand, another study showed that giomers have less color change and the most significant color change was obtained at 4 weeks caused by cola ${ }^{[21]}$, there is no significant color change when using mouthwash ${ }^{[2]}$, as a restorative material, compared to a resin, they react similarly to coffee pigmentation and both have acceptable color change, but when bleaching is performed it affects the translucency of both materials ${ }^{[23]}$ and compared to glass ionomer it has a better finish and less color change ${ }^{[24]}$. Prolonged use of multivitamin syrups and effervescent tablets negatively affects hardness and roughness in both giomer and glass ionomer ${ }^{[25]}$. The intensity of the lamp influences the dimensional changes that the giomer undergoes; greater dimensional changes have been reported if the high mode $(0.23 \%)$ is used when light curing compared to the low mode $(0.17 \%)$. The shrinkage of the giomer (Beautifil II) was lower than Fuji II LC when using low mode ${ }^{[26]}$. It is important to avoid disinfecting the cavity with chlorhexidine before applying the material ${ }^{[27]}$ or contact with aluminum chloride (in class $\mathrm{V}$ cavities) because it increases the space between the material and the tooth ${ }^{[28]}$. Nevertheless, it has high quality mechanical and optical properties ${ }^{[29]}$.

\subsubsection{Glass Ionomer}

Glass ionomer, when combined with conditioner, is most successful when used in atraumatic restorative treatment (ART) ${ }^{[30]}$. Bonding $10 \%$ glass ionomer filler to resin-based composites increases physical properties such as hardness, flexural strength and compressive strength ${ }^{[31]}$. The shrinkage effect of Ketac Molar Aplicap and Ketac Molar Quick Aplicap glass ionomers is less than that of polymerized RMGIC when the material is light cured ${ }^{[26]}$. However, the latter has higher flexural strength, although lower compressive strength than conventional ${ }^{[19]}$ and, compared to a resin, has higher occlusal wear ${ }^{[32]}$. In terms of marginal adaptation, RMGICs are better than giomers ${ }^{[33]}$. In the absence of saliva contamination, less microleakage is present in hybrid glass ionomers and RMGIC compared to high viscosity GI ${ }^{[34]}$. Compared to giomer and other materials, it has greater color change when using mouth rinses ${ }^{[23]}$. It has a lower survival rate compared to resins; however, it prevents further tissue disintegration in teeth with MIH and contributes to improved patient cooperation ${ }^{[35]}$.

The giomer has a greater esthetic advantage than glass ionomer as less color change has been reported, in addition, it has less shrinkage. These qualities may be favorable for its greater longevity. On the other hand, GI proves to be very useful especially in the treatment of MIH.

\subsection{Chemical Properties}

\subsubsection{Giomer}

Fluoride, strontium and silicate ions provide remineralization of dentin ${ }^{[36]}$. The varnish containing this filler, in its calcium type (PRG-Ca), prevents demineralization around materials containing this compound ${ }^{[37]}$. As a varnish, it induces the release of fluoride and, in addition, has the capacity to recharge when in contact with fluoride pastes, varnishes or mouthwashes ${ }^{[38]}$. As a sealant, it has a higher fluoride recharging property compared to sealants containing GI ${ }^{[39]}$. According to a comparison of four different sealers, the sealer containing S-PRG was found to be the best because of the type and amount of ions it releases ${ }^{[5]}$, these ions inhibit enamel demineralization ${ }^{[40]}$.In addition, it has been reported that adhesives with this filler show good adhesion [13]. 
Another advantage is that it has antimicrobial activity which inhibits biofilm and bacterial growth ${ }^{[41,42]}$.

\subsubsection{Glass Ionomer}

In a recent investigation, it was found that glass ionomer as a pulp capping does not cause postoperative pulp sensitivity, even in very deep cavities, indicating that it is biocompatible ${ }^{[43]}$. As a sealer, it has been shown to have greater fluoride release compared to sealers containing S-PRG ${ }^{[39]}$. They are highly cariostatic, in addition, fluoride inhibits bacterial growth and triclosan adhesion provides positive results ${ }^{[19]}$. The addition of antimicrobial compounds provides clinical benefits, however, this may decrease the mechanical properties of the GI and even decrease the release of fluoride, which has an effect against bacteria ${ }^{[44]}$.

The ability of both materials to release fluoride represents a favorable property for the treatment of carious lesions and even MIH. Another advantage of both materials is the ability to recharge fluoride ions, which represents a possibility to better control caries susceptibility.

\subsection{Applications \\ 3.5.1 Giomer}

S-PRG-filled materials have been shown to be effective in the remineralization of enamel in primary teeth and can therefore be considered as a material for caries prevention treatment ${ }^{[45}$,

${ }^{38]}$. Some studies have found that it has less long-term success compared to resins, however, it can be used for cervical and occlusal restorations and even in primary teeth ${ }^{[12]}$, clinical and radiographic success has been reported both at 6 and 12 months in class II cavities in primary molars ${ }^{[46]}$ and even maintain acceptable qualities after 13 years of follow-up ${ }^{[47]}$. Likewise, the restorative system proved to be effective in class I and II cavities in permanent molars which were followed up for 18 months ${ }^{[14]}$. On the other hand, it does not appear to be a good alternative as a sealant in erupting teeth [48]. Positive results have also been reported for 7 months when used as a restoration in teeth with $\mathrm{MIH}$ including the elimination of sensitivity ${ }^{[49]}$. S-PRG cements used as pulp capping induce tertiary dentin ${ }^{[50]}$.

\subsubsection{Glass Ionomer}

Glass ionomers used for the restoration of class II cavities in primary molars have been shown to have a good response to the presence of secondary caries ${ }^{[51]}$. High viscosity glass ionomers are also used as a restoration after selective carious tissue removal in patients with MIH and have been found to be effective in maintaining the structural integrity of the crown for 2 years ${ }^{[52]}$. In addition, they are well accepted for application in (ART) ${ }^{[44]}$ even in patients with ECC with follow-up for 4 years ${ }^{[53]}$. However, it has better outcome when using high viscosity GI30. RMGIC is successful when used as a base for proximal restorations in primary teeth ${ }^{[54]}$.

Both giomer and glass ionomer can be used for restorations in primary and permanent teeth. However, there are currently more publications reporting success using glass ionomer because giomer is a relatively new material on the market.

\section{Conclusions}

Both giomer and glass ionomer are fluoride releasing materials and have the ability to be refilled with pastes, varnishes, etc. The PRG filler of giomer, creating a stable glass ionomer phase, when used as a restorative material has a greater esthetic advantage than glass ionomer. Glass ionomer has a wider variety of applications as a restorative material, cement, pulp capping and pit and fissure sealant.

\section{References}

1. Shiiya $T$, Tomiyama $K$, Iizuka J, Hasegawa $H$, Kuramochi E, Fujino F, et al. Effects of resin-based temporary filling materials against dentin demineralization. Dent Mater J 2016;35(1):70-75.

2. Savas S, Colgecen O, Yasa B, Kucukyilmaz E. Color stability, roughness, and water sorption/solubility of glass ionomer-Based restorative materials. Niger J Clin Pract 2019;22(6):824-832.

3. Peres MA, Macpherson LMD, Weyant RJ, Daly B, Venturelli R, Mathur MR, et al. Oral diseases: a global public health challenge Lancet 2019;394(10194):249260.

4. Van der Tas JT, Elfrink MEC, Heijboer AC, Rivadeneira F, Jaddoe VWV, Tiemeier H, et al. Foetal, neonatal and child vitamin D status and enamel hypomineralization. Community Dent Oral Epidemiol 2018;46(4):343-351.

5. Chen KJ, Gao SS, Duangthip D, Lo ECM, Chu CH. Prevalence of early childhood caries among 5-year-old children: A systematic review. J Investig Clin Dent 2019;10(1):e12376.

6. Tinanoff N, Baez RJ, Diaz Guillory C, Donly KJ, Feldens CA, McGrath C, et al. Early childhood caries epidemiology, aetiology, risk assessment, societal burden, management, education, and policy: Global perspective. Int J Paediatr Dent 2019;29(3):238-248.

7. Villanueva Gutiérrez T, Barrera Ortega CC, García Pérez A, González-Aragón Pineda AE. Relationship between Molar Incisor Hypomineralization (MIH) severity and cavitated carious lesions in schoolchildren. Acta Odontol Latinoam 2019;32(3):133-140.

8. Amaechi BT, Kasundra H, Joshi D, Abdollahi A, Azees PAA, Okoye LO. Effectiveness of S-PRG FillerContaining Toothpaste in Inhibiting Demineralization of Human Tooth Surface. Open Dent J 2018;12:811-819.

9. Krämer $\mathrm{N}$, Schmidt $\mathrm{M}$, Lücker $\mathrm{S}$, Domann $\mathrm{E}$, Frankenberger R. Glass ionomer cement inhibits secondary caries in an in vitro biofilm model. Clin Oral Investig 2018;22(2):1019-1031.

10. Shea BJ, Reeves BC, Wells G, Thuku M, Hamel C, Moran J, et al. AMSTAR 2: a critical appraisal tool for systematic reviews that include randomised or nonrandomised studies of healthcare interventions, or both. BMJ 2017;358:j4008.

11. Ikemura K, Tay FR, Endo T, Pashley DH. A review of chemical-approach and ultramorphological studies on the development of fluoride-releasing dental adhesives comprising new pre-reacted glass ionomer (PRG) fillers. Dent Mater J 2008;27(3):315-339.

12. Francois P, Fouquet V, Attal JP, Dursun E. Commercially Available Fluoride-Releasing Restorative Materials: A Review and a Proposal for Classification. Materials (Basel) 2020;13(10):2313.

13. Ikemura K, Tay FR, Kouro Y, Endo T, Yoshiyama M, Miyai $\mathrm{K}$, et al. Optimizing filler content in an adhesive system containing pre-reacted glass-ionomer fillers. Dent Mater 2003;19(2):137-146.

14. Akimoto N, Ohmori K, Hanabusa M, Momoi Y. An eighteen-month clinical evaluation of posterior restorations with fluoride releasing adhesive and composite systems. Dent Mater J 2011;30(3):411-418.

15. Colceriu Burtea L, Prejmerean C, Prodan D, Baldea I, Vlassa M, Filip M, et al. New Pre-reacted Glass 
Containing Dental Composites (giomers) with Improved Fluoride Release and Biocompatibility. Materials (Basel) 2019;12(23):4021.

16. Sidhu SK, Nicholson JW. A Review of Glass-Ionomer Cements for Clinical Dentistry. J Funct Biomater 2016;7(3):16.

17. Moberg M, Brewster J, Nicholson J, Roberts H. Physical property investigation of contemporary glass ionomer and resin-modified glass ionomer restorative materials. Clin Oral Investig 2019;23(3):1295-1308.

18. Wetzel R, Eckardt O, Biehl P, Brauer DS, Schacher FH. Effect of poly(acrylic acid) architecture on setting and mechanical properties of glass ionomer cements. Dent Mater 2020;36(3):377-386.

19. Ching HS, Luddin N, Kannan TP, Ab Rahman I, Abdul Ghani, NRN. Modification of glass ionomer cements on their physical-mechanical and antimicrobial properties. J Esthet Restor Dent 2018;30(6):557-571.

20. Gönülol N, Ozer S, Sen Tunc E. Water Sorption, Solubility, and Color Stability of Giomer Restoratives. J Esthet Restor Dent 2015;27(5):300-306.

21. Hotwani $\mathrm{K}$, Thosar N, Baliga S. Comparative in vitro assessment of color stability of hybrid esthetic restorative materials against various children's beverages. J Conserv Dent 2014;17(1):70-74.

22. Ulusoy NB, Arikan V, Akbay Oba A. Effect of mouthwashes on the discolouration of restorative materials commonly used in paediatric dentistry. Eur Arch Paediatr Dent 2018;19(3):147-153.

23. ElSayad II. Color and translucency of finished and unfinished esthetic restorative materials after staining and bleaching. Saudi Dent J 2018;30(3):219-225.

24. Priyadarshini BI, Jayaprakash T, Nagesh B, Sunil CR, Sujana V, Deepa VL. One-year comparative evaluation of Ketac Nano with resin-modified glass ionomer cement and Giomer in noncarious cervical lesions: A randomized clinical trial. J Conserv Dent 2017;20(3):204-209.

25. Gurdogan-Guler EB, Bayrak GD, Unsal M., SelviKuvvetli S. Effect of pediatric multivitamin syrups and effervescent tablets on the surfacemicrohardness and roughness of restorative materials: An in vitro study. J Dent Sci 2020;(40).

26. Spajić J, Prskalo K, Šariri K, Par M, Pandurić V, Demoli N. Dimensional Changes of Glass Ionomers and a Giomer during the Setting Time. Acta Stomatol Croat 2018;52(4):298-306.

27. Kimyai S, Pournaghi-Azar F, Naser-Alavi F, Salari A. Effect of disinfecting the cavity with chlorhexidine on the marginal gaps of $\mathrm{Cl} \mathrm{V}$ giomer restorations. J Clin Exp Dent 2017;9(2):e202-e206.

28. Kimyai S, Pournaghi-Azar F, Mohammadi N, Babri M. Effect of hemostatic agent on marginal gaps of class $\mathrm{V}$ giomer restorations. J Clin Exp Dent 2017;9(5):e672e676.

29. Condò R, Cerroni L, Pasquantonio G, Mancini M, Pecora A, Convertino A, et al. A Deep Morphological Characterization and Comparison of Different Dental Restorative Materials. Biomed Res Int 2017;2017:7346317.

30. Saber AM, El-Housseiny AA, Alamoudi NM. Atraumatic Restorative Treatment and Interim Therapeutic Restoration: A Review of the Literature. Dent J (Basel) 2019;7(1):28.

31. Verma R, Azam MS, Kumar SR, Patnaik A. Mechanical and thermo-mechanical characterization of glass ionomer-filled dental composite. Polymer composites 2018;2019;40(8):3361-3367.

32. Dermata A, Papageorgiou SN, Fragkou S, Kotsanos N. Comparison of resin modified glass ionomer cement and composite resin in class II primary molar restorations: a 2-year parallel randomised clinical trial. Eur Arch Paediatr Dent 2018;19(6):393-401.

33. Rusnac ME, Gasparik C, Irimie AI, Grecu AG, Mesaroş AŞ, Dudea D. Giomers in dentistry - at the boundary between dental composites and glass-ionomers. Med Pharm Rep 2019;92(2):123-128.

34. Çelik Ç, Bayraktar Y, Özdemir BE. Effect of Saliva Contamination on Microleakage of Open Sandwich Restorations. Acta Stomatol Croat 2020;54(3):273-282.

35. Linner T, Khazaei Y, Bücher K, Pfisterer J, Hickel R, Kühnisch J. Comparison of four different treatment strategies in teeth with molar-incisor hypomineralizationrelated enamel breakdown-A retrospective cohort study. Int J Paediatr Dent 2020;30(5):597-606.

36. Shiiya $\mathrm{T}$, Tomiyama $\mathrm{K}$, Iizuka J, Hasegawa $\mathrm{H}$, Kuramochi E, Fujino F, et al. Effect of the coating material on root dentin remineralization in vitro. Am J Dent 2014;27(5):258-262.

37. Kawasaki K, Kambara M. Effects of ion-releasing toothcoating material on demineralization of bovine tooth enamel. Int J Dent 2014;2014:463149.

38. Wakamatsu N, Ogika M, Okano T, Murabayashi C, Kondo T, Iinuma M. Effect of tooth surface coating material containing S-PRG filler on white spot lesions of young permanent teeth. Pediatr Dent $\mathrm{J}$ [Internet] 2018;28(1):40-45.

39. Patil SS, Kontham UR, Kontham RK, Patil SS, Kamble SP. Fluoride release and fluoride-recharging ability of three different sealants. J Indian Soc Pedod Prev Dent 2020;38(3):247-252.

40. Kaga M, Kakuda S, Ida Y, Toshima H, Hashimoto M, Endo $\mathrm{K}$, et al. Inhibition of enamel demineralization by buffering effect of S-PRG filler-containing dental sealant. Eur J Oral Sci 2014 Feb;122(1):78-83.

41. Shimazu K, Oguchi R, Takahashi Y, Konishi K, Karibe H. Effects of surface reaction-type pre-reacted glass ionomer on oral biofilm formation of Streptococcus gordonii. Odontology 2016;104(3):310-317.

42. Kitagawa H, Miki-Oka S, Mayanagi G, Abiko Y, Takahashi N, Imazato S. Inhibitory effect of resin composite containing S-PRG filler on Streptococcus mutans glucose metabolism. J Dent 2018;70:92-96.

43. Ribeiro APD, Sacono NT, Soares DG, Bordini EAF, de Souza Costa CA, Hebling J. Human pulp response to conventional and resin-modified glass ionomer cements applied in very deep cavities. Clin Oral Investig 2020;24(5):1739-1748.

44. Tüzüner T, Dimkov A, Nicholson JW. The effect of antimicrobial additives on the properties of dental glassionomer cements: a review. Acta Biomater Odontol Scand 2019;5(1):9-21.

45. Murayama R, Nagura Y, Yamauchi K, Moritake N, Iino $\mathrm{M}$, Ishii $\mathrm{R}$, et al. Effect of a coating material containing surface reaction-type pre-reacted glass-ionomer filler on prevention of primary enamel demineralization detected by optical coherence tomography. J Oral Sci 2018;60(3):367-373.

46. Inthihas SK, G Nirmala SVS, Rudhravarm VR. Clinical and Radiographic Success of Three Adhesive Restorative Materials in Primary Molar Proximal Lesions: A 
Randomized Clinical Trial. Contemp Clin Dent 2019;10(3):483-488.

47. Gordan VV, Blaser PK, Watson RE, Mjör IA, McEdward DL, Sensi LG, et al. A clinical evaluation of a giomer restorative system containing surface prereacted glass ionomer filler: results from a 13-year recall examination. J Am Dent Assoc 2014;145(10):1036-1043.

48. Topal BG, Kirzioglu Z. Evaluation of the fissure sealants applied to erupting permanent molars in accordance to eruption stages: A prospective study. Niger J Clin Pract 2019;22(11):1495-1502.

49. Arce-Izaguirre $M$, Torres-Ramos G, Alvino-Vales $M$, Barzola-Loayza M. Giómeros fluidos en la eliminación de sensibilidad en molar permanente afectada con Hipomineralización Incisivo Molar (HIM). Reporte de caso. Int J Interdiscip Dent 2020;13(2):95-98.

50. Takahashi $\mathrm{Y}$, Okamoto $\mathrm{M}$, Komichi S, Imazato $\mathrm{S}$, Nakatsuka T, Sakamoto S, et al. Application of a direct pulp capping cement containing S-PRG filler. Clin Oral Investig 2019;23(4):1723-1731.

51. Jones G, Taylor G. Glass ionomer or composite resin for primary molars. Evid Based Dent 2018;19(3):86-87.

52. Durmus B, Sezer B, Tugcu N, Caliskan C, Bekiroglu N, Kargul B. Two-Year Survival of High-Viscosity Glass Ionomer in Molar Incisor Hipomineralized-molars. Med Princ Pract 2020 May 15.

53. Faustino-Silva DD, Figueiredo MC. Atraumatic restorative treatment-ART in early childhood caries in babies: 4 years of randomized clinical trial. Clin Oral Investig 2019;23(10):3721-3729.

54. Ortiz-Ruiz AJ, Pérez-Guzmán N, Rubio-Aparicio M, Sánchez-Meca J. Success rate of proximal tooth-coloured direct restorations in primary teeth at 24 months: a metaanalysis. Sci Rep 2020;10(1):6409. 